\section{Re-wilding: a bold plan that needs native megafauna}

SIR - In their Commentary article ${ }^{\alpha} \mathrm{Re}$ wilding North America" (Nature 436, 913-914; 2005), Josh Donlan and colleagues offer a vision of a North America populated with roaming throngs of megafauna such as cheetahs, elephants and tortoises. This is a welcome change from conservationists' too often reactive and rearguard action against a tidal wave of human impacts and extinctions. But the proposal neglects people's needs and political realities. Being bolder and more ambitious is the right idea - but Donlan and his colleagues have the wrong vision.

The Great Plains of North America are, in many areas, dominated by ranchlands and agricultural fields, as Steven Shay points out in Correspondence (Nature 437, 476; 2005).

There are substantial social and economic problems associated with the presence of large animals on private lands, including, as the authors acknowledge, the enormous costs of building and maintaining fences to control them, as well as the environmental problems highlighted by Christopher Irwin Smith in Correspondence (Nature 437, 318; 2005).

Most studies have shown that importing non-native species comes at huge economic and ecological cost.

A positive vision can catalyse a movement and generate real change, so it is critical for such visions to be grounded in reality.

As an alternative, we -11 Smith postdoctoral fellows and three senior scientists with the Nature Conservancy (see https:// webspace.utexas.edu/mas $2687 /$ SmithTNC_ coauthors.html) - suggest that conservation efforts in North America should focus on restoring the megafauna native to this continent and ensuring that native species retain the evolutionary potential to adapt to novel environmental conditions, including those created by humans.

This approach, already adopted by the World Wildlife Fund and the American Prairie Foundation (see Nature 437, 476; 2005), is more likely to be successful in the long run, as it respects the ecological conditions and environmental context to which these species are already adapted. Martin A. Schlaepfer

(an behalf of TNC-Smith Fellows, classes 2003/4), University of Texas, Austin, Texas 78712, USA

\section{Evolution was fine, just not in the case of humans}

SIR - Your News story “Fresh scope" (Nature 436, 451; 2005) and Editorial "Keeping religion out of science class" (Nature 436, 753; 2005) misrepresent the
Scopes case, or 'monkey trial'. The substitute science teacher John Scopes was convicted and fined, not for teaching evolution in itself, but for his presentation of Darwin's views on the descent of humanity.

In the 1920s, Tennessee, Arkansas and Mississippi passed laws banning the teaching of human evolution in public schools.

According to Tennessee's Butler Law, enacted in 1925 , it was "unlawful ... to teach any theory that denies the story of the Divine Creation of man as taught in the Bible ${ }^{\text {. As }}$ noted by the Tennessee Supreme Court in the Scopes trial, "this enactment only intended to forbid teaching that men descended from a lower order of animals" (R. Moore, M. Jensen \& J. Hatch BioScience 53, 766-771; 2003).

After the Scopes trial, the laws banning the teaching of human evolution remained in effect for more than 40 years. But teaching students about Darwin's general principle of evolution, with reference to non-human organisms, has never been illegal in the United States.

U. Kutschera

Institute of Biology, University of Kassel, Heinrich-Plett-Strasse 40,

D-34109 Kassel, Germany

\section{NIH moved quickly to help researchers after Katrina}

SIR - I would like to add some details to your News story "New Orleans researchers fight to salvage work from submerged labs" (Nature 437, 300; 2005) regarding efforts made by the National Institutes of Health (NIH) to assist its grantees in the Hurricane Katrina disaster zone.

Although it is true that the Federal Emergency Management Agency (FEMA) has primary responsibility for dealing with the immediate structural damage from a catastrophe - as I was quoted as saying this quote does not do justice to the efforts by the NIH to promote a quick and full recovery from the storm. Leaders of damaged research institutions were contacted promptly and assured that the $\mathrm{NIH}$ would be at their sides in restoring facilities and research projects. The NIH immediately moved to inform grantees of the resources available, from grant extensions to temporary placements in the NIH intramural programme or other institutions.

The response to Katrina will require effort, flexibility and cooperation, but first and foremost we need profound commitment and solidarity. The NIH and the entire biomedical research community will stand together with those stricken by this disaster and by Hurricane Rita.

Elias Zerhouni

National Institutes of Health, 9000 Rockville Pike, Bethesda, Maryland 20892, USA

\section{Indian players in some of IT and biotech's top teams}

SIR — Your Outlook feature "Among the best: strong bonds" (Nature 436, 494; 2005), quotes Govindarajan Padmanaban as saying "Indian scientists on the whole do not integrate in large groups".

I disagree with this generalization. Indian scientists and engineers are widely employed across diversified disciplines, all over the heavily industrialized Western world. Many of today's successful small and medium-sized IT and biotech companies were founded by Indian entrepreneurs, and elsewhere senior Indian executives have played key roles in running larger organizations.

A few familiar names in this ever-growing list are: Vinod Khosla, co-founder of Sun Microsystems; Sabeer Bhatia, founder of Hotmail; Arun Netravali, former president of Bell Labs; and Arun Sarin, chief executive of Vodafone.

The success of these companies, which to a large extent relies on teamwork and interpersonal skills, is, in itself, clear evidence that we Indians are great team players. Other contributory factors could be our familiarity with the English language (English is the de facto official language across India, thanks to the British Raj), our inborn spirituality and the extended-family culture that teaches cooperation, mutual respect and interdependence.

Mukund Mehrotra

Portola Pharmaceuticals,

270 East Grand Avenue,

South San Francisco, California 94080, USA

\section{System to rank scientists was pedalled by Jeffreys}

SIR - Jorge Hirsch's index for measuring research achievement, as described in your News Story "Index aims for fair ranking of scientists" (Nature 436, 900; 2005) was used by the geophysicist Harold Jeffreys for recording his cycling prowess, $n$ being the highest number of days on which he had cycled $n$ or more miles. I think he told me, some 35 years ago, that his $n$ was 70 and that he first had the idea from his fellow cyclist, the astrophysicist Arthur Eddington.

A.W. F. Edwards

Gonville and Caius College,

University of Cambridge,

Cambridge CB2 1TA, UK

Contributions to Correspondence may be submitted to corres@nature.com.They should be nolonger than $\mathbf{5 0 0}$ words, and ideally shorter. They should be signed by no more than three authors; preferably by one. Published contributions are edited. 